\title{
Sağlık Bilimleri Fakültesi Öğrencilerinin Psikiyatrik Hastalıklara İlişkin Alg1 ve Tutumları
}

\author{
Melike BOZTILKİ ${ }^{1}$, Elif ARDIÇ², Begüm GAMIşs ${ }^{2}$ ve Ekin ÇEVIK ${ }^{4}$
}

Öz

Bu çalışmanın amacı, sağlık bilimleri alanında eğitim almakta olan öğrencilerin damgalama davranışlarının ölçülmesi yoluyla, damgalama davranışı ve eğitim arasındaki ilişkiyi incelemektir. Araştırmanın evrenini İstanbul Anadolu Yakası'nda bulunan bir Vakıf Üniversitenin Sağlık Bilimleri Fakültesi'nde öğrenim görmekte olan 1643 öğrenci oluşturmuştur. Çalışmaya katılmayı kabul eden 1435 öğrenci ise örneklemini oluşturmuştur. Veriler 2017-2018 akademik yılı, Güz ve Bahar dönemlerinde toplanmıştır. Veri toplama aracı olarak damgalama davranışını ölçen Akıl Hastalıkları Hakkında Kanaat Ölçeği ve Sosyo-Demografik Soru Formu kullanılmıştır. Öğrencilerin yaş ortalaması $20,54 \pm 2,37$ ve \%83,3’ü ( $\mathrm{n}=1196)$ kadındır. Çalışmanın alt boyutlarında, cinsiyete, bölümlere, sinıflara, "Akıl Hastalıkları ve Ruh Sağlı̆̆ı” ile ilgili müfredatta ders varlığına, tanıdık hasta varlığına göre anlamlı farklılıklar bulunmuştur. Bu çalışmanın sonuçları; Sağlık Bilimleri Fakültesi’nde öğrenim gören öğrencilerin psikiyatri hastalarına ve hastalıklarına yönelik tutumlarında olumlu yönde gelişmenin sınırlı düzeyde kaldığını, öğrencilerin reddedici ve dışlayıcı tutumlarının aldıkları eğitime rağmen sürdüğünü göstermiştir. Bu bağlamda söz konusu alanlardaki lisans müfredatlarının "damgalamayla mücadele" konusundaki yeterliliğinin sorgulanmaya açık olduğu görülmüştür.

Anabtar Kelimeler: Ruh Sağlığı, Eğitim, Damgalama

\section{Perception and Attitudes of the Faculty of Health Sciences Students on Psychiatric} Diseases

\begin{abstract}
The aim of this study is to investigate the relationship between stigmatization and education by measuring the stigmatization behavior of students studying in the field of health sciences. 1435 students studying at the Faculty of Health Sciences of a university in Istanbul constitute the sample of the research. The study was conducted between September 2017 and June 2018. To measure stigmatization behavior, Opinions About Mental Illness (OMI) and socio-demographic questionnaire were used. The average age of the students was $20.54 \pm 2.37$ and $83.3 \%(\mathrm{n}=1196)$ were female. Significant differences were found in the sub-dimensions of the study according to gender, departments, classes, and the existence of courses in the curriculum related to Mental Health. According to this study's results, positive attitude development of the students of Faculty of Health to psychiatric patients and their illnesses remained limited, and that the students' rejection and exclusionary attitudes continued despite the education they received. In this context, it was seen that the undergraduate curricula in the mentioned fields were open to question the ability to fight against stigma.
\end{abstract}

Key Words: Mental Health, Education, Stigma

\section{Atıf İçin / Please Cite As:}

Boztilki, M., Ardıç, E., Gamiş, B. ve Çevik, E. (2021). Sağlık bilimleri fakültesi öğrencilerinin psikiyatrik hastalıklara ilişkin alg1 ve tutumları. Manas Sosyal Araştırmalar Dergisi, 10(4), 2449-2458.

Geliş Tarihi / Received Date: 13.05.2020

Kabul Tarihi / Accepted Date: 28.06.2021

\footnotetext{
${ }^{1}$ Dr. Arş. Görevlisi - Üsküdar Üniversitesi Sağlık Bilimleri Fakültesi Sosyal Hizmet Bölümü, mboztilki@gmail.com

ORCID: 0000-0002-7892-3847

2 Dr. Arş. Gör. - Marmara Üniversitesi Sağlık Bilimleri Fakültesi, elifardiccc@gmail.com (Sorumlu Yazar)

ORCID: 0000-0003-3327-115X

${ }^{3}$ Doktora öğrencisi - Arş. Görevlisi - Üsküdar Üniversitesi Sağllk Bilimleri Fakültesi, begumgamis@gmail.com

(iD) ORCID: 0000-0001-8191-1591

${ }^{4}$ Doktora öğrencisi - Arş. Görevlisi. - Üsküdar Üniversitesi Sağlık Bilimleri Fakültesi, ekin.cevik@uskudar.edu.tr

(iD) ORCID:0000-0003-1591-0069
} 
"Ë̆itim, ögrenilip unutulanlardan geriye kalanlarder." [B.F. Skinner]

\section{Giriş}

\section{Damgalama Kavramı}

Damgalama ve damgalamaya ilişkin kavramlar, ilk kez sosyoloji alanı tarafindan tanımlanmıştır. Kavramı ilk kez kullanan sosyolog Goffman'a göre (1963, s. 11) damgalama bireyin sahip olduğu; a) karakter özellikleri, b) fiziksel özellikler veya c) belli bir gruba üyelik sebepleriyle ortaya çıkabilmekte ve damgalanan bireyin toplumun geri kalanından daha aşağı ve tehlikeli olduğu kabullerine dayanmaktadır. Sonraki dönemde sağlık alanı içinde tanımlanan 'psikiyatri hastalarına yönelik damgalama davranışı' ise bilgi (bilgisizlik), tutum (önyarg1) ve davranış sorunları (ayrımclık) içeren bir bileşim olarak açıklanmakta ve psikiyatri hastalarının tedavi olmaları önündeki birincil engeller arasında gösterilmektedir. Psikiyatri hastalarına yönelik damgalama, toplumdan bireye doğru yönelen 'sosyal damgalama' ile; bireyin kendisine yönelttiği ‘öz damgalama' olmak üzere ikiye ayrilmaktadır (Gaebel, Roessler ve Sartorius, 2017, s. 29) Sosyal damgalama genel olarak; akıl hastalıklarının bireyin kendi hataları sonucu ortaya çıktığı, tedavi edilemez olduğu ve akıl hastası bireyin tehlikeli olduğu yargıları etrafinda şekillenen korku, kaçınma, reddetme davranışlarını içerirken, öz damgalama (DeFreitas, DeLeon ve Ajayi, 2018, s. 3); akıl hastalığ1 yaşamakta olan bireylerin kendilerine yönelik geliştirdikleri utanç, yetersizlik duygularını içermektedir (Papish, Kassam, Modgill, Vaz ve Zanussi, 2013, s. 7).

Damgalamanın psikiyatri hastaları üzerindeki olumsuz etkilerinden bazıları şunlardır; a) Bireylerin tetkik/tedavi amacıyla psikiyatri kliniklerine başvuru eğilimini düşürmektedir. $\mathrm{Bu}$ da tedavi olma ihtimallerini düşürmektedir. b) Akıl hastalıklarına ilişkin geliştirilen korku, endişe gibi sebeplerle akıl hastalı̆̆1 olan bireylerin iş bulma ihtimalleri düşüktür. c) Akıl hastalığı olan bireylerin hissedebilecekleri dışlanma korkusu, hayata karşı tutuk, çekingen bir tavır benimsemelerine ve karşlaşacakları firsatları değerlendirememelerine neden olabilmektedir. $\mathrm{Bu}$ da bireylerin yaşamlarından duydukları tatmini azaltmakta; kendilerini gerçekleştirme ihtimallerini düşürmektedir.

\section{Damgalamanın Eğitimle Ortadan Kaldırılabilmesi İhtimali Üzerine}

Bireylerin kendi sağlıklarına ilişkin davranışlarının eğitim durumlarıyla doğrudan ilişkili olduğunu; daha yüksek düzey eğitime sahip bireylerin sağılı davranışı geliştirmeye daha yatkın olduklarını gösteren pek çok çalışma bulunmaktadır (Wolfe ve Haveman, 2002, s. 1) Ancak sağllk konusunda alınan eğitimin bireyin dışa yönelik davranışlarında da değişim oluşturacağını garanti etmemektedir. Zira yapılan bazı araştırmalar, sadece eğitimsiz bireylerin değil, eğitimli, özellikle de sağlık eğitimli bireylerin yoğun şekilde damgalama davranışı geliştirebildiklerini göstermektedir. Buna ek olarak, eğitimin damgalama davranışında sebep olduğu azalma eğiliminin geçici olduğunu ve belli bir zaman sonunda damgalama içeren davranışların tekrar ortaya çıktığını gösteren pek çok araştırma bulunmaktadır.

ABD'de tıp öğrencilerinin akıl hastalıklarına yaklaşımlarını anlamak amacıyla yapılan bir araştırmada, akıl hastalıklarına yönelik damgalamanın çeşitli eğitimlerden sonra düşüş gösterdiği, ancak fiziksel hastalıklara yönelik olumsuz algiya oranla daha yüksek seviyede kalmaya devam ettiği görülmüştür içermektedir (Papish, Kassam, Modgill, Vaz ve Zanussi, 2013, s. 6). Yunanistan'da üniversite öğrencileriyle yapılan bir çalışma psikiyatri hastalarına aşina olmanın, akıl hastalarına yönelik sosyal mesafeyi azalttığını göstermiştir. Buna ek olarak yakın çevresinde psikiyatri hastası olan kişilerde, genel olarak psikiyatri hastalarına yönelik sosyal damgalama ve aşağı görme eğiliminin azaldığı; ancak öğrencilerin genel olarak bu hastaların iyileşebilecekleri ve rehabilite edilmeleri gerekliliğiyle ilgili fikirlerinin olumsuz olmaya devam ettiği görülmüştür (Anagnostopoulos ve Hantzi, 2011, s. 4). Yine tıp öğrencileri arasında psikiyatri alanının en az tercih edilen uzmanlık alanı olmasını, bir çeșit örtülü damgalama olarak değerlendirmek mümkündür. Bu durumun sonucu olarak yorumlanabilecek şekilde psikiyatri hastaları, kendileriyle ilgilenen uzmanların, doktorlar da dâhil olmak üzere damgalayıc1 davranışlar sergilediklerini; örneğin muayene olmak için diğer hastalara kıyasla daha uzun süre beklemek zorunda kaldıklarını belirtmişlerdir (Bowland, Hensley, Johnson ve Fleming, 2010, s. 16). Diğer taraftan akıl hastalıkları konusunda halka verilen eğitimlerin etkilerinin de kısa süreli olduğu, insanlar bilişsel boyutta kendilerini damgalama davranışından uzakta tanımlasalar dahi, bir akıl hastasıyla ilk karşılaşmalarında sosyal mesafeyi arttırıcı davranışlar geliştirdikleri görülmüştür (Davidson, 2002, s. 22). Dolayısıyla yalnızca ve özellikle bilişsel düzeyde kalan bir eğitimin damgalama davranışını ortadan kaldırdığını ve/veya kesin bir azalış döngüsüne taşıdığını söylemek mümkün görünmemektedir. 
Eğitim-damgalama davranışı ilişskisini inceleyen bazı çalışmalar, eğitimle tutum arasındaki bu paradoksal durumu açıklamak üzere, tavır kutuplaşması (attitude polarization) adıverilen fenomen üzerinde durmaktadır. Bir konu hakkında ayrıntılı bilgi alındıktan sonra fikirlerin daha net şekilde olumlu veya olumsuz olarak şekillenebildiğini savunan bu yaklaşıma göre, bir konu hakkında bilgi verilirken insanlar var olan yargılarını güçlendirecek bilgileri işlemeye ve tutmaya daha eğilimli olabilmektedirler (Lord, Ross ve Lepper, 1979, s. 2098). Bu durumda örneğin, şizofreni hastalarına ilişkin olumsuz düşüncelere sahip bir birey, şizofreniyle ilgili aldığı bir eğitimden sonra olumsuz düşüncelerinde ne kadar haklı olduğunu düşünebilir ve böylelikle, negatif algısı güçlenebilir. Dolayısıyla psikiyatrik hastalıklara ilişkin önyargıların eğitimle kırılabileceğine yönelik inanç bu kavram ışığında değerlendirildiğinde, eğitimin, beklenenin aksine olumsuz önyargiları güçlendirmesi riskinin de bulunduğu görülmektedir.

\section{Damgalama Davranışının Ölçümü ve Sinirlıliklar}

Damgalama davranışını ölçmeye yönelik yapılan araştırmalar, genellikle varsayımsal durumlarda sergilenecek tutumu belirlemeye yönelik şekilde gerçekleşmektedir. Ancak bir kişinin varsayımsal bir durumda takınacağını belirttiği tavırla, aynı durumu gerçek yaşamda deneyimlediğinde göstereceği tepkinin örtüşmemesi ihtimalinin göz ardı edilmesi mümkün değildir. Örneğin akıl hastalarına yönelik damgalama davranışı geliştirmediğini iddia eden bir kişinin, psikiyatrik hastalığ olan bir bireyle arkadaş olmak isteyip istemeyeceği, bu durumdaki bir kişiye ne kadar güven duyacağına ilişkin bir tahminde bulunmak mümkün görünmemektedir. Dolayısıyla bu ve benzeri araştırmalar, varsayımsal durumlar üzerinden şekillendiği için gerçek yaşamdaki tutum ve davranışları belirleme konusundaki güvenilirlikleri tartışmalıdır. Bunun yanında eğitimin davranış üzerindeki etkisinin devamlılığına yönelik bir ölçüm içeren yapıda olmaması da, bu ve benzeri araştırmaların sinırlılıkları arasındadır.

Araştırmada şu soruların cevaplanması amaçlanmaktadır;

1. Öğrencilerin psikiyatri konularını içeren dersler almaları, akıl hastalıkları ve akıl hastalarına yönelik alg1 ve tutumunu etkilemekte midir?

2. Psikiyatri hastalarına yönelik algıda, eğitim süresince staj, inceleme, gözlem gibi ders içerikleri sebebiyle bu hastalarla karşılaşan öğrencilerin algıları, bu tarz hastalarla karşılaşmayan öğrencilerin algilarından farklı midir?

3. Eğer bir farklılaşma mevcutsa, yönü ne şekildedir?

4. Sağlık alanındaki lisans eğitimi, öğrencilerin psikiyatri hastalarına yönelik algılarını etkilemekte midir?

\section{Yöntem}

\section{Araştırmanın Türü}

$\mathrm{Bu}$ çalışma, üniversite öğrencilerinin psikiyatrik hastalıklara ilişkin tutum ve görüşlerini belirlemek amacıyla tanımlayıcı tipte yapılmışır.

\section{Araştırmanın Yeri ve Zamanı}

$\mathrm{Bu}$ araştırma İstanbul Anadolu Yakası'nda bulunan bir vakıf üniversitesinde 01.09.2017- 30.06.2018 tarihleri arasında yürütülmüştür.

\section{Evren - Örneklem}

Araştırmanın evrenini Üniversitenin SBF'nin Çocuk Gelişimi (ÇG), Dil ve Konuşma Terapisi (DKT), Hemşirelik, Ergoterapi, İş Sağllğı ve Güvenliği (ISG), Odyoloji, Sosyal Hizmet (SH) ve Sağllk Yönetimi (SY) bölümlerinde öğrenim görmekte olan 1643 öğrenci oluşturmaktadır. Çalışmaya katılmayı kabul eden 1435 öğrenci ise örneklemini oluşturmuştur.

\section{Çalışmaya Dâhil Olma Kriterleri}

18 yaş ve üzeri olmak, çalısmaya gönüllü katılmayı kabul etmek, ÇG, DKT, Hemşirelik, Ergoterapi, İSG, Odyoloji, SH ve SY bölümlerinden birinde öğrenci olmak.

\section{Dişlama Kriterleri}

1. sınıftan 4.sınıfa kadar öğrencisi olmayan / yeni açılan bölümlerde (Perfüzyon, Ortez-Protez, Beslenme ve Diyetetik, Fizyoterapi ve Rehabilitasyon) öğrenim gören öğrenciler ile; 
SBF kayıtlı öğrencisi olup, "Hazırlık” sınıfinda öğrenim gören öğrenciler örneklem dışı tutulmuştur.

\section{Veri Toplama Araçları}

Araştırmada veri toplama aracı olarak, Sosyodemografik Bilgi Formu ve Akıl Hastalıkları Hakkında Kanaat Ölçeği kullanılmıştır.

\section{Sosyodemografik Bilgi Formu}

Form 17 sorudan oluşmaktadır (yaş, cinsiyet, bölüm, sınıf, akıl hastalıkları ve ruh sağlığı hakkında bilgi durumu, bu konu hakkında daha önce ders alıp almadığı ve bir uzman tarafindan tanılanmış "Akıl Hastalığı" olan tanıdığın varlığına ilişkin soruları içermektedir.

\section{Akı1 Hastalıkları Hakkında Kanaat Ölçeği (Opinions About Mental Illness- OMI)}

OMI Cohen ve Struening (1962, s. 349) tarafindan başlangıçta, sağlık personelinin akıl hastalığına karşı tutumlarını değerlendirmek için geliştirilmiştir. Ölçeğin Türkçe formunun psikometrik özellikleri 1986 yılında Arıkan tarafindan çalışılmıştı (Arıkan, Özdemir ve Satır, 1989, s. 411). Arıkan çalışmasında, pek çok araştırmacının OMl'nin psikiyatri alanında ruh hastalarına ilişkin tutumların ölçümünde kullanılan en güvenilir ve geçerli araç olduğunu vurgulamış ve bu nedenle ölçeğin oldukça yaygın bir kullanıma sahip olduğunu belirtmiştir. Ölçek yöntemsel açıdan şu varsayıma dayanmaktadır; ruhsal bozukluğu olan hastalara ilişkin düşünce ve tutumlar çok boyutludur. Bu nedenle tanımlanmaları, çok faktörlü bir analize dayalı olarak yapılmalıdır. Likert tipi 51 maddeden oluşan ölçek tutumları 6 farklı boyutta incelemektedir. Söz konusu boyutlar şunlardır:

Otoriterlik (Faktör A): Bu faktör ruh hastalarının normal insandan farklı ve ondan aşağı olduğu görüşünü yansıtmaktadır.

Koruyuculuk, Kollayıc1lı (Faktör B): Bu faktör "şansız ve güçsüz görünen" ruh hastalarına karşı dinsel ve insancıl bir ideolojiye dayalı bir bakış açısını/tutumu yansıtmaktadır.

Ruh Sağllğı İdeolojisi (Faktör C): Böyle bir ideoloji, ruh sağlığ1 profesyonellerinin felsefesini yansıtmaktadır. Buna göre ruh hastalığı da diğer hastalıklar gibidir. Dolayısıyla bu, çok farklı bir hastalık kategorisi gibi görülmemektedir.

Sosyal Kısıt/ayıc1lik (Faktör D): Bu faktör gerek hospitalizasyon sırasında, gerekse sonrasında toplumu özellikle de aileyi korumak için ruh hastalarının kısıtlanması gerektiği görüşünü yansıtmaktadır. Bu görüş ile ruh hastalarının bir tehlike olduğu ileri sürülmektedir.

Kişilerarası Etiyoloji (Faktör E): Bu faktör de ruh hastalığının özellikle çocukluk çağındaki bozuk ana baba ve çocuk ilişkisine dayalı olarak ortaya çıktığı inancını yansıtmaktadır. Dolayısıyla ruh hastalığının oluşumunda yalnızca birey değil çevresi de pay sahibidir.

Faktör Formül A = $67-\Sigma(1,6,9,11,16,19,21,39,43,46,48) ; \mathrm{B}=31+\Sigma(26,32,34,36,37,40$, 49) $-\Sigma(2,12,17,18,22,27,47) ; \mathrm{C}=48+(31)-\Sigma(3,13,23,28,33,38,44,50), \mathrm{D}=47+\Sigma(8,41)-\Sigma$ $(4,7,14,24,29,42,45,51) ; \mathrm{E}=43-\Sigma(5,10,15,20,25,30,35)$

Böylece eğer bir kişi Faktör A'daki tüm maddelere kesinlikle katılırsa alacağı puan 67-11 veya 56 olacaktır. Eğer tüm maddelere karşıysa puanı 67-66 veya 1 olacaktır. Yüksek puan, o faktöre ilişkin olumlu bir tutumu yansitmaktadır.

OMI ölçeği, özellikle faklı grupların ruh hastalarına ve hastalıklarına karşı tutumlarını başarıyla ölçmektedir.

\section{Veri Analizi}

Veriler SPSS 24.0 paket programıla analiz edilmiştir. Sürekli değişkenler ortalama \pm standart sapma, ortanca (en küçük - en büyük değerler) ve kategorik değişkenler sayı ve yüzde olarak ifade edilmiştir. Verilerin normal dağglıma uygunluğu Kolmogorov Smirnov, Shapiro-Wilk testleri ve qq, pp grafikleri ile incelenmiştir. Parametrik test varsayımları sağlandığında bağımsız grup farklılıklarının karşılaştırılmasında Bağımsız gruplarda t testi ve Tek Yönlü Varyans analizi kullanılmıştır. Parametrik test varsayımları sağlanmadığında ise bağımsız grup farklılıklarının karşılaştırılmasında Mann Whitney U testi ve Kruskal Wallis Varyans Analizi kullanılmışır. Kategorik değişkenler arasındaki farklılıkların incelenmesinde Ki kare analizi kullanılmıştır. Sürekli değişkenler arasındaki ilişkilerin incelenmesinde ise 
Pearson ve Spearman Korelasyon Analizleri kullanılmıştır. Tüm analizlerde $\mathrm{p}<0,05$ istatistiksel olarak anlamlı kabul edilmiştir.

\section{Bulgular}

Çalışmaya katılan öğrencilere ilişkin sosyodemografik özellikler aşağıdaki gibidir.

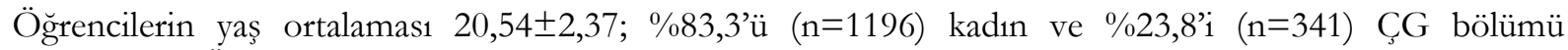
öğrencisidir. Öğrencilerin \% 70,2'si (n=1008) okuduğu bölümde şu ana kadar akıl hastalıkları ve ruh sağlğg ile ilgi ders almamısken; \%68,9'u (n= 989) müfredata bu konu ile ilgili ders eklenmesinin gerekli olduğunu belirtmiştir. \%86,1’i (n=1236) Akıl Hastalıkları ve Ruh Sağlı̆̆ ile ilgili yeterli bilgiye sahip olmadığını düşünmektedir.(Tablo 1).

Tablo 1. SBF Ögrencilerinin Sosyo-Demografik Özellikleri $(N=1435)$

\begin{tabular}{|c|c|c|c|}
\hline & & $\mathrm{AO} \pm \mathrm{S}$ & Med (min -maks) \\
\hline \multirow[t]{2}{*}{ Yaş } & & $20,54 \pm 2,37$ & $20(17-39)$ \\
\hline & & $\mathrm{n}$ & $\%$ \\
\hline \multirow{2}{*}{ Cinsiyet } & Kadin & 1196 & 83,3 \\
\hline & Erkek & 239 & 16,7 \\
\hline \multirow{8}{*}{ Bölüm } & Hemşirelik & 205 & 14,3 \\
\hline & ÇG & 341 & 23,8 \\
\hline & SY & 220 & 15,3 \\
\hline & Ergoterapi & 160 & 11,1 \\
\hline & $\mathrm{DKT}$ & 139 & 9,7 \\
\hline & Odyoloji & 84 & 5,9 \\
\hline & İSG & 50 & 3,5 \\
\hline & $\mathrm{SH}$ & 236 & 16,4 \\
\hline \multirow{4}{*}{ Sinif } & 1.sinif & 460 & 32,1 \\
\hline & 2.sinif & 405 & 28,2 \\
\hline & 3.sinif & 289 & 20,1 \\
\hline & 4.sinif & 281 & 19,6 \\
\hline \multirow{2}{*}{ Ruh Sağlığı Ve Akıl Hastalıkları İle İlgili Ders Varlığ1 } & Evet & 427 & 29,8 \\
\hline & Hayır & 1008 & 70,2 \\
\hline \multirow{3}{*}{ Müfredata Ruh Sağlığı Ve Akıl Hastalıkları İle İlgili Ders Eklenmesi } & Gerekli & 989 & 68,9 \\
\hline & Gereksiz & 145 & 10,1 \\
\hline & Fikrim yok & 301 & 21,0 \\
\hline \multirow{2}{*}{ Ruh Sağlığı Ve Akıl Hastalıkları İle İlgili Daha Önce Alınan Eğitim } & Evet & 121 & 8,4 \\
\hline & Hayır & 1314 & 91,6 \\
\hline \multirow{2}{*}{ Ruh Sağlığı Ve Akıl Hastalıkları İle İlgili Yeterli Bilgi Varlığı } & Evet & 199 & 13,9 \\
\hline & Hayır & 1236 & 86,1 \\
\hline \multirow{3}{*}{ Akıl Hastalığı Olan Tanıdık Varlığ1 } & Yok & 1077 & 75,1 \\
\hline & Ailemde & 41 & 2,9 \\
\hline & Akrabamda & 317 & 22,1 \\
\hline Toplam & & 1435 & 100,0 \\
\hline
\end{tabular}

Ölçeğe ait alt boyutların bölümlere göre farkllıkları incelendiğinde; Otoriterlik, Sosyal Kısıtlayıcılık ve Kişilerarası Etiyoloji alt boyutlanında istatistiksel olarak ileri derecede anlamlı farkllık; Koruyuculuk ve Kollayıc1lk alt boyutunda ise, istatistiksel olarak anlamlı farklılık bulunmuştur. İkili incelemelerde; Otoriterlik alt boyutunda DKT bölümündeki öğrencilerin değerleri Hemşirelik, SY, Odyoloji ve SH bölümlerinde okuyan kişilere göre düşük bulunmuştur. Koruyuculuk alt boyutunda, Ergoterapi bölümündeki öğrencilerin değerlerinin Hemşirelik, DKT, İSG ve SH bölümlerinde okuyan kişilere göre yüksek bulunmuştur. Sosyal Kısıtlayıcılık alt boyutunda, Ergoterapi bölümündeki öğrencilerin değerlerinin Hemşirelik, ÇG ve SH bölümlerinde okuyan kişilere göre düşük; SH bölümünde okuyan öğrencilerin değerlerinin ise SY, Ergoterapi ve DKT bölümlerinde okuyan kişilere göre yüksek bulunmuştur. Kişilerarası Etiyoloji alt boyutunda ise, DKT bölümündeki ögrencilerin değerlerinin hemşirelik, ÇG, SY, Ergoterapi, Odyoloji, ISG ve SH bölümlerinde okuyan kişilere göre düşük bulunmuştur (Tablo 2). 
BOZTILLKI, ARDIÇ, GAMIŞ ve ÇEVIKK

Sağlık Bilimleri Fakültesi Öğrencilerinin Psikiyatrik Hastalıklara İlişkin Algı ve Tutumları

Tablo 2. Ölçek Alt Boyutlarmın Bölümlere Göre Karşılaștımlması

\begin{tabular}{|c|c|c|c|c|c|c|c|c|c|}
\hline $\begin{array}{l}\text { Alt } \\
\text { Boyutlar }\end{array}$ & $\begin{array}{l}\text { Hemşirelik } \\
(n=205) \\
\text { AO } \pm S\end{array}$ & $\begin{array}{l}\text { ÇG } \\
(n=341) \\
\text { AO } \pm S\end{array}$ & $\begin{array}{l}S Y \\
(n=220) \\
A O \pm S\end{array}$ & $\begin{array}{l}\text { Ergotera } \\
\text { pi } \\
(\mathrm{n}=160) \\
\mathrm{AO} \pm \mathrm{S}\end{array}$ & $\begin{array}{l}\text { DKT } \\
(n=139) \\
\text { AO } \pm S\end{array}$ & $\begin{array}{l}\text { Odyoloji } \\
(n=84) \\
\text { AO } \pm S\end{array}$ & $\begin{array}{l}\text { İSG } \\
(n=50) \\
A O \pm S\end{array}$ & $\begin{array}{l}\text { SH } \\
(n=236) \\
\text { AO } \pm S\end{array}$ & $\begin{array}{ll}\mathrm{p} & \mathrm{F} \\
\mathbf{X}^{2} & \end{array}$ \\
\hline Otoriterlik & $31,97 \pm 6,88$ & $\begin{array}{l}30,58 \pm \\
6,52\end{array}$ & $\begin{array}{l}31,87 \pm \\
6,34\end{array}$ & $\begin{array}{l}30,18 \pm \\
6,56\end{array}$ & $\begin{array}{l}28,58 \pm \\
6,92\end{array}$ & $\begin{array}{l}31,81 \pm \\
6,52\end{array}$ & $\begin{array}{l}31,46 \pm \\
6,23\end{array}$ & $\begin{array}{l}31,2 \pm \\
6,94\end{array}$ & $\begin{array}{l}.0001 * * \\
\mathrm{~F}=4,56\end{array}$ \\
\hline $\begin{array}{l}\text { Koruyucul } \\
\text { uk } \\
\text { Kollayıcılik }\end{array}$ & $41,18 \pm 7,25$ & $\begin{array}{l}42,39 \pm \\
6,1\end{array}$ & $\begin{array}{l}42,49 \pm \\
6,97\end{array}$ & $\begin{array}{l}43,23 \pm \\
6,66\end{array}$ & $\begin{array}{l}41,5 \pm \\
6,04\end{array}$ & $\begin{array}{l}41,06 \pm \\
7,59\end{array}$ & $\begin{array}{l}41,52 \pm \\
7,07\end{array}$ & $\begin{array}{l}41,31 \pm \\
8,33\end{array}$ & $\begin{array}{l}.028^{*} \\
\chi^{2}=15,656\end{array}$ \\
\hline $\begin{array}{l}\text { Ruh Sağliğ1 } \\
\text { İdeolojisi }\end{array}$ & $30,64 \pm 4,59$ & $\begin{array}{l}31,38 \pm \\
4,8\end{array}$ & $\begin{array}{l}31,76 \pm \\
4,83\end{array}$ & $\begin{array}{l}31,24 \pm \\
5,32\end{array}$ & $\begin{array}{l}30,72 \pm \\
4,44\end{array}$ & $\begin{array}{l}30,99 \pm \\
4,73\end{array}$ & $\begin{array}{l}31,62 \pm \\
5,58\end{array}$ & $\begin{array}{l}31,08 \pm \\
4,84\end{array}$ & $\begin{array}{l}.107 \\
\chi^{2}=11,82 \\
\end{array}$ \\
\hline $\begin{array}{l}\text { Sosyal } \\
\text { Kisitlayicili } \\
\mathrm{k}\end{array}$ & $25,84 \pm 5,98$ & $\begin{array}{l}25,84 \pm \\
5,72\end{array}$ & $\begin{array}{l}24,44 \pm \\
6,14\end{array}$ & $\begin{array}{l}23,69 \pm \\
5,88\end{array}$ & $\begin{array}{l}24,77 \pm \\
5,76\end{array}$ & $\begin{array}{l}26,11 \pm \\
6,3\end{array}$ & $\begin{array}{l}25,88 \pm \\
5,76\end{array}$ & $\begin{array}{l}27,27 \pm \\
6,48\end{array}$ & $\begin{array}{l}.0001^{* *} \\
\mathrm{~F}=6,668\end{array}$ \\
\hline $\begin{array}{l}\text { Kişilerarası } \\
\text { Etiyoloji }\end{array}$ & $20,12 \pm 5,32$ & $\begin{array}{l}19,94 \pm \\
5,43\end{array}$ & $\begin{array}{l}19,38 \pm \\
5,52\end{array}$ & $\begin{array}{l}18,98 \pm \\
5,02\end{array}$ & $\begin{array}{l}17,07 \pm \\
5,46\end{array}$ & $\begin{array}{l}20,83 \pm \\
4,95\end{array}$ & $\begin{array}{l}20,2 \pm \\
4,99\end{array}$ & $\begin{array}{l}19,63 \pm \\
5,61\end{array}$ & $\begin{array}{l}.0001^{* *} \\
\mathrm{~F}=5,874\end{array}$ \\
\hline
\end{tabular}

$\mathrm{p}<.01^{* *}, \mathrm{p}<.05^{*}, \mathrm{~F}:$ Tek Yönlü Varyans Analizi; $\chi^{2}:$ Kruskal Wallis Varyans Analiz

Ölçeğe ait alt boyutların sınıflara göre farklılıkları incelendiğinde; Koruyuculuk ve Kollayıcıllk ve Ruh Sağlığı İdeolojisi alt boyutlarında sınıflar arasında istatistiksel olarak ileri derecede anlamlı farklılık bulunmuştur. İkili incelemelerde; Koruyuculuk ve Kollayıcılık alt boyutunda 4.sınıfların değerlerinin 2., 3. ve 1. sınıflara göre düşük bulunmuştur. Ruh Sağlığı İdeolojisi alt boyutunda ise, 1.sınıfların değerlerinin 2., 3. ve 4. sinıflara göre yüksek, 4.sinıfların değerlerinin de 2., 3. ve 1. sinfflara göre düşük bulunmuştur (Tablo 3).

Tablo 3. Ölçek Alt Boyutlarının Sınıflara Göre Karşılaştımlması

\begin{tabular}{|c|c|c|c|c|c|}
\hline Alt Boyutlar & $\begin{array}{l}\text { 1.sinif }(n=460) \\
A O \pm S\end{array}$ & $\begin{array}{l}\text { 2.sinif }(n=405) \\
A O \pm S\end{array}$ & $\begin{array}{l}3 . \text { sinif } \\
(n=289) \\
A O \pm S\end{array}$ & $\begin{array}{l}\begin{array}{l}\text { 4.sinif } \\
(n=281)\end{array} \\
\mathrm{AO} \pm \mathrm{S}\end{array}$ & $\begin{array}{l}\text { Gruplar Arasi } \\
\mathrm{p}\end{array}$ \\
\hline Otoriterlik & $31,55 \pm 6,37$ & $30,73 \pm 6,76$ & $30,31 \pm 6,62$ & $30,91 \pm 7,2$ & $\mathrm{p}=.083 \quad(\mathrm{~F}=2,234)$ \\
\hline $\begin{array}{l}\text { Koruyuculuk, } \\
\text { Kollayıcilık }\end{array}$ & $43,07 \pm 6,79$ & $42,01 \pm 6,74$ & $42,17 \pm 6,86$ & $39,83 \pm 7,43$ & $\mathrm{p}=.0001^{* *}\left(\chi^{2}=36,48\right)$ \\
\hline $\begin{array}{l}\text { Ruh Sağllğ1 } \\
\text { İdeolojisi }\end{array}$ & $32,11 \pm 4,74$ & $31,12 \pm 4,71$ & $31,18 \pm 4,41$ & $29,8 \pm 5,25$ & $\mathrm{p}=.0001^{* *}(\mathrm{~F}=13,712)$ \\
\hline Sosyal Kisıtlayıcılık & $25,17 \pm 6,3$ & $25,51 \pm 5,89$ & $25,8 \pm 6,23$ & $25,91 \pm 5,86$ & $\mathrm{p}=.345(\mathrm{~F}=1,106)$ \\
\hline $\begin{array}{l}\text { Kişilerarası } \\
\text { Etivoloji }\end{array}$ & $19,74 \pm 5,41$ & $19,59 \pm 5,43$ & $19,14 \pm 5,46$ & $19,38 \pm 5,47$ & $\mathrm{p}=.502(\mathrm{~F}=0,786)$ \\
\hline
\end{tabular}

$\mathrm{p}<.01^{* *} \mathrm{~F}$ : Tek Yönlü Varyans Analizi; $\chi^{2}$ :Kruskal Wallis Varyans Analizi

Ölçeğe ait alt boyutların "Akıl Hastalıkları ve Ruh Sağlığı” ile ilgili ders varllğına göre farklılıkları incelendiğinde; Otoriterlik ve Ruh Sağllğ1 İdeolojisi alt boyutlarında istatistiksel olarak ileri derecede anlamlı farklılık bulunmuştur (Tablo 4).

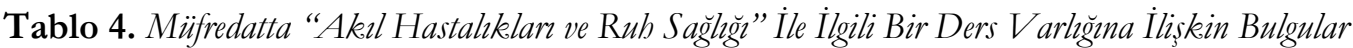

\begin{tabular}{lcccc}
\hline Alt Boyutlar & $\begin{array}{c}\text { Evet } \\
(\mathbf{n = 4 2 7}) \\
\mathbf{A O} \pm \mathbf{S}\end{array}$ & $\begin{array}{c}\text { Hayır } \\
(\mathbf{n = 1 0 0 8}) \\
\mathbf{A O} \pm \mathbf{S}\end{array}$ & $\mathbf{p}$ & $\mathbf{t}$ \\
\hline Otoriterlik & $30,01 \pm 6,83$ & $31,34 \pm 6,62$ & $.001^{* *}$ & $-3,455$ \\
\hline Koruyuculuk, Kollayıcılık & $41,42 \pm 6,82$ & $42,18 \pm 7,07$ & .061 & $-1,873$ \\
\hline Ruh Sağlı̆̆ İdeolojisi & $30,42 \pm 5,17$ & $31,51 \pm 4,65$ & $.0001^{* *}$ & $-3,761$ \\
\hline Sosyal Kısıtlayıcılık & $25,09 \pm 5,95$ & $25,73 \pm 6,14$ & .071 & $-1,804$ \\
\hline Kişilerarası Etiyoloji & $19,59 \pm 5,35$ & $19,47 \pm 5,48$ & .682 & 0,409 \\
\hline p<.01** t: Bağımsız Gruplarda t testi & & & &
\end{tabular}

Ölçeğe ait alt boyutların, lisans müfredatına bu konu ile ilgili ders eklenmesi konusunda düşünce durumlarına göre farklılıkları incelendiğinde; Koruyuculuk ve Kollayıcılık Ruh Sağlığı İdeolojisi ve Sosyal Kısıtlayıcılık alt boyutlarında istatistiksel olarak ileri derecede anlamlı farklılık bulunmuştur (Tablo 5). 
Tablo 5. Lisans Müfredatma "Akel Hastalkklar ve Ruh Sağhğı” İle Illgili Ders Eklenmesi Konusunda Düs̆̈̈nce Durumu

\begin{tabular}{|c|c|c|c|c|c|}
\hline Alt Boyutlar & $\begin{array}{l}\text { Gerekli } \\
(n=989) \\
\mathrm{AO} \pm \mathrm{S}\end{array}$ & $\begin{array}{l}\text { Gereksiz } \\
(n=145) \\
\mathrm{AO} \pm \mathrm{S}\end{array}$ & $\begin{array}{l}\text { Fikrim yok } \\
(\mathrm{n}=301) \\
\mathrm{AO} \pm \mathrm{S}\end{array}$ & $\mathbf{P}$ & $\mathrm{X}^{2}$ \\
\hline Otoriterlik & $30,7 \pm 6,66$ & $31,61 \pm 7,36$ & $31,44 \pm 6,52$ & $\begin{array}{l}\mathrm{p}=.112 \\
\mathrm{~F}=2,191\end{array}$ & \\
\hline $\begin{array}{l}\text { Koruyuculuk, } \\
\text { Kollayıc1lık }\end{array}$ & $42,52 \pm 6,8$ & $39,81 \pm 7,51$ & $41,13 \pm 7,16$ & $\begin{array}{l}\mathrm{p}=.0001^{* *} \\
\chi^{2}=21,164\end{array}$ & \\
\hline $\begin{array}{l}\text { Ruh Sağlloğ1 } \\
\text { İdeolojisi }\end{array}$ & $31,56 \pm 4,7$ & $30,86 \pm 5,58$ & $30,13 \pm 4,73$ & $\begin{array}{l}\mathrm{p}=.0001 * * \\
\mathrm{X}^{2}=17,190\end{array}$ & \\
\hline $\begin{array}{l}\text { Sosyal } \\
\text { Kisitlayıcılık }\end{array}$ & $25,15 \pm 6,07$ & $26,68 \pm 6,48$ & $26,26 \pm 5,86$ & $\begin{array}{l}\mathrm{p}=.001 * * \\
\mathrm{~F}=6,778\end{array}$ & \\
\hline $\begin{array}{l}\text { Kişileraras1 } \\
\text { Etiyoloji } \\
\end{array}$ & $19,54 \pm 5,4$ & $19,61 \pm 6,24$ & $19,33 \pm 5,16$ & $\begin{array}{l}\mathrm{p}=.807 \\
\mathrm{~F}=0,214\end{array}$ & \\
\hline
\end{tabular}

p <.01** F: Tek Yönlü Varyans Analizi; $\chi^{2}:$ Kruskal Wallis Varyans Analizi

\section{Tartışma, Sonuç ve Öneriler}

Ruhsal hastalıklara yönelik inançlar son 20 yıl boyunca daha ayrıntılı olarak araştırılmaya başlanmış ve cinsiyet, ırk, eğitim, din, yaş gibi faktörlerin algıları etkileyebileceği belirtilmiștir. Tutum ve inançlar özellikle ergenlik döneminde oluşmaya başlar, yetişkinliğin erken dönemlerinde yavaş yavaş kristalleşir ve bu aşamadan sonra değiş̧tirilmeleri güçleşir (Martin, 2010, s. 259). Bu bilgiler 1şığında çalışmamız, sağlık alanında ve lisans düzeyinde alınan bir eğitimin, edinilmiş inanç ve tutumları ne derece etkilediği konusunda fikir sahip olmak amacıyla gerçekleştirilmiştir.

Çalışmaya katılan SBF öğrencilerinin ( $\mathrm{n}=1435)$ yaş ortalamaları 20,54 $\pm 2,37$ olarak gerçekleşmiştir. Öğrencilerin \%83,3’ü (n=1196) kadın, \%68,9’u erkektir.

Ölçeğe ait alt boyutların bölümlere göre farklıllkları incelendiğinde; Otoriterlik, Koruyuculuk ve Kollayıc1lk, Sosyal Kısıtlayıc1lı ve Kişilerarası Etiyoloji alt boyutlarında bölümler arasında istatistiksel olarak anlamlı farklılık bulunmuştur. İkili incelemelerde; Otoriterlik alt boyutunda DKT bölümündeki öğrencilerin değerlerinin, Hemşirelik, SY, Odyoloji ve SH bölümlerinde okuyan kişilere göre anlamlı düzeyde düşük bulunmuştur. Koruyuculuk alt boyutunda, Ergoterapi bölümündeki öğrencilerin değerlerinin Hemşirelik, DKT, İSG ve SH bölümlerinde okuyan kişilere göre anlamlı düzeyde yüksek bulunmuştur. Sosyal kıstllayıcılık alt boyutunda, Ergoterapi bölümündeki öğrencilerin değerlerinin Hemşirelik, ÇG ve SH bölümlerinde okuyan kişilere göre anlamlı düzeyde düşük; SH bölümünde okuyan öğrencilerin değerlerinin ise SY, Ergoterapi ve DKT bölümlerinde okuyan kişilere göre anlamlı düzeyde yüksek bulunmuştur. Bu ilginç bir noktadır; zira $\mathrm{SH}$ bölümü müfredatı incelendiğinde psikiyatrik hastalıklara ilişkin doğrudan (Tıbbi ve Psikiyatrik Sosyal Hizmet, Madde Bağımlılığı dersleri gibi) veya dolaylı olarak (ayrımcilık, toplumsal damgalama gibi içeriklere sahip dersler) çok sayıda dersin yer aldığ1 görülmektedir. Buna rağmen SH öğrencilerinin, müfredatlarında doğrudan psikiyatrik hastalıklar veya damgalama/ayrımcilık konularında ders olmayan SY, DKT ve Ergoterapi bölümlerindeki öğrencilere kıyasla daha yüksek düzeyde kısıtlayıcı ve otoriter bir yaklaşım benimsedikleri bulunmuştur. Yine aynı şekilde, fiziksel ve ruhsal sağllk konusunda en fazla bilgiye ve stajlar sebebiyle en yüksek deneyime sahip olan Hemşirelik öğrencilerinin de, otoriter ve kısıtlayıcı yaklaşıma, psikiyatrik hastalıklara ilişkin doğrudan eğitim almayan bölümlerin öğrencilerinden daha yüksek düzeyde eğilim gösterdikleri görülmektedir. Kişilerarası Etiyoloji alt boyutunda ise, DKT bölümündeki öğrencilerin değerlerinin Hemşirelik, ÇG, SY, Ergoterapi, Odyoloji, İSG ve SH bölümlerinde okuyan kişilere göre anlamlı düzeyde düşük bulunmuştur.

Ölçeğe ait alt boyutların sınıflara göre farklılıkları incelendiğinde; Koruyuculuk ve Kollayıcılık ile Ruh Sağlığı ideolojisi alt boyutlarında sınıflar arasında istatistiksel olarak anlamlı farklılık bulunmuştur. İkili incelemelerde; koruyuculuk alt boyutunda 4.sınıfların değerlerinin 2, 3. ve 1. sinıflara göre anlamlı düzeyde düşük bulunmuştur. Koruyuculuk ve Kollayıcılık boyutu "şansız ve güçsüz görünen" ruh hastalarına karş1 dinsel ve insancıl bir ideolojiye dayalı bir bakış açısını/tutumu yansıtmaktadır. Temelinde psikiyatrik bilgi ve deneyimi olmayan ya da az olan grupta ruh sağlığı bozuk olan bireye yönelik acıma, yardım gibi hümanistik duygular yer almaktadır. Dolayısıyla bu sonucu, öğrencilerin teorik ve uygulamalı eğitimlerinin etkisiyle akıl hastalıklarına yönelik algılarında, duygu merkezli yaklaşımdan uzaklaşmalarının sonucu olarak okumak mümkün görünmektedir. Çalışmanın ruh sağlığı ideolojisi alt boyutunda, 4.sınıfların değerleri 1., 2. ve 3. sınıflara göre anlamlı düzeyde düşük gerçekleşmiştir. Eğitime dayalı bilgi ve uygulama derslerine 
dayalı deneyim arttıkça damgalama içeren davranışların arttığını gösteren bu sonuç, atıf kuramını destekler niteliktedir. Bu konudaki literatüre bakıldığında ise, sonuçların birbiri ile çok da tutarlı olmadığ1 görülmektedir. Örneğin Bostancı ve Aştı’nın (2004, s.89) yaptıkları çalışmada psikiyatri kliniğinde çalışan hemşirelerin ruh sağlığ ideolojisi alt boyutu puan ortalamaları, psikiyatri dışı kliniklerde çalışan hemşirelerden düşük çıkmıştır. Bu sonuç psikiyatri kliniğinde çalışan hemşirelerin sahip olmaları beklenen profesyonel bakış açısıyla örtüşmemektedir. Doğan vd. (1994, s. 87) çalışmalarında psikiyatri stajı yapmış olmanın öğrencilerin tutumlarında olumlu yönde bir değişiklik yaptı̆̆ını değerlendirirken; Duman ve ark. (2019, s. 141) ise tıp eğitiminin ruhsal hastalıklara yönelik tutumlarda olumlu yönde bir etkisi olmadığını belirtmiştir. Arrkan (1989, s. 411 ) sosyal hizmet uzmanı olacak öğrencilerle yaptığı çalışmada, staj yapmış olmanın otoriterlik ve kısıtlayıcılık tutumları puan ortalamaları arasında staj yapmış olma lehine olumlu bir fark bulurken diğer faktörler arasında bir fark bulamamıştır. Farklı üniversitelerde yapılan araştırmalara dayanan ve tutarsız görünen bu sonuçlar, ülkemizde sağlık alanında verilen lisans eğitiminin teorik ve uygulama sonuçlarının değerlendirilmesinin yalnızca bilişsel düzeyde değil; tutum, algı ve davranış düzeylerinde de yapılması gerekliliğini düşündürmektedir. Zira fiziksel veya toplumsal sağlık alanında çalışacak bir profesyonelin bilgi düzeyi kadar, hizmet verdiği gruplar hakkındaki tutum ve davranışları da hizmetin kalite ve verimliliğini belirleyecektir.

Ölçeğin alt boyutlarının "akıl hastalıkları ve ruh sağlığg” ile ilgili ders varlığına göre farklılıkları incelendiğinde; otoriterlik alt boyutlarında istatistiksel olarak anlamlı farklılık bulunamamıştır. Dersi olmayan öğrencilerin otoriterlik alt boyutu değerleri, dersi olan öğrencilere göre anlamlı düzeyde yüksektir. Bostancı ve Aş̧ı'nın (2004, s. 90) çalışmasında psikiyatri kliniklerinde çalışan hemşirelerin otorite alt boyutu, psikiyatri dışı kliniklerde çalışan hemşirelerden düşük bulunmuştur.

Öğrencilerin, lisans müfredatına akıl hastalıkları ve ruh sağlğı ile ilgili ders eklenmesi konusunda düşünce durumlarına göre farklılıkları incelendiğinde; Koruyuculuk ve Kollayıcllık, Ruh Sağlığı İdeolojisi ve Sosyal Kısıtlayıcillk alt boyutlarında düşünceler arasında istatistiksel olarak anlamlı farklılık bulunmuştur. İkili incelemelerde; koruyuculuk alt boyutunda dersin gerekli olduğunu düşünen öğrencilerin değerlerinin, dersin gereksiz olduğunu düşünen ve fikri olmayan kişilere anlamlı düzeyde yüksek bulunmuştur. Ruh sağlığ1 ideolojisi alt boyutunda dersin gerekli olduğunu düşünen öğrencilerin değerlerinin fikri olmayan kişilere anlamlı düzeyde yüksek bulunmuştur. Sosyal Kısıtlayıcilık alt boyutunda ise, dersin gerekli olduğunu düşünen öğrencilerin değerlerinin, dersin gereksiz olduğunu düşünen ve fikri olmayan kişilere göre anlamlı düzeyde düşük bulunmuştur. Yüksel vd. (2015, s. 30) çalışmasında; öğretim elemanlarının psikolojiye veya psikiyatriye ilgi duyup kitap okuma ve okumama durumu ile Sosyal Kısıtlayıcılık boyutu ölçek puanı arasında istatistiksel açıdan anlamlı bir fark olduğu saptanmıştır. $\mathrm{Bu}$ bulguya göre ruh sağlı̆̆ alanıyla ilgili kitap okumayan öğretim elemanları toplumu ve özellikle de aileyi korumak için ruh hastalarının kısıtlanması gerektiği ve ruh hastalarının tehlikeli olduğu ile ilgili bir görünü savunmaktadır. Bilge vd. (2012, s. 9)çalışmasında ruh sağlığ ve hastalıkları dersini (RSHD) alan ögrencilerde dersi aldıktan sonra ruh hastalarına yönelik olumlu inanç oranında artış bulunmuş ve inanç değişikliği yaşayan bu öğrencilerin \%85,1'i RSHD hakkındaki düşüncelerinin olumsuz inançlarında azalma yönünde olduğunu belirtmiştir. Aynı çalışmada öğrencilerin çoğunluğu $(\% 94,6)$ RSHD'nin gerekli bir ders olduğunu düşünmektedir. Literatürde psikiyatri bilgi ve becerisine sahip olmanın önyarg1 ve yanlş inanışların önlenmesinde etkili olduğu vurgulanmaktadır.

İnsanlar belirli inanç ve tutumlarla doğmazlar. İnanç ve tutumlar; gözlem ve bilişsel öğrenme gibi çeşitli yollarla elde edilir. Bhugra (1989, s. 9) tutumlardaki değişmelerin yayılması için birden fazla neslin geçmesi gerektiğini ve bilginin devamlı verilmesi gerektiğini söylemiştir. Damgalama davranışının azalması amacıyla ögrencilerin pek çok konudaki inanç ve tutumlarının zaten oluşmuş olduğu görülmektedir. Psikiyatrik hastalıkların fiziksel hastalıklardan farklı olmadığı bilgisinin eğitimin ilk basamaklarından itibaren bireylere kazandırılmasının önemli olduğu düşünülmektedir. Bu bağlamda, ilköğretim ikinci kademeden itibaren farklılıklara sayg1 ve insan hakları temelli derslerde, psikiyatrik hastalıklara ilişkin bilgilerin öğrencilerin seviyesine uygun şekilde yer alması konusunda araştırma ve çalışmalar yapılması önerilmektedir. Böylelikle lisans düzeyinde değiştirilmesi zorlaşan yargılara, henüz şekillenme aşamasında müdahale etmek mümkün olacaktır. Diğer taraftan çalışmamızın ve benzer yapıdaki araştırmaların gösterdiği üzere kişinin yakın çevresinde psikiyatri hastalarının olması, olumsuz yargıları azaltıcı bir etkendir. Bu nedenle özellikle sağlık alanında çalısacak lisans öğrencilerinin, psikiyatri hastalarılla daha sık bir arada bulunabileceği ve ortak hedefler etrafında buluşabileceği ruh sağlığı içerikli proje, ödev gibi çalışmaların teşvik edilmesinin faydalı olacağ1 düşünülmektedir. 


\section{Etik Beyan}

"Sağhlk Bilimleri Fakültesi Öğrencilerinin Psikiyatrik Hastalkklara Ilişkin Alğ ve Tutumları" başlıklı çalışmanın yazım sürecinde bilimsel kurallara, etik ve alıntı kurallarına uyulmuş; toplanan veriler üzerinde herhangi bir tahrifat yapılmamış ve bu çalışma herhangi başka bir akademik yayın ortamına değerlendirme için gönderilmemiştir. Gerekli olan etik kurul izinleri Üsküdar Üniversitesi Girişimsel Olmayan Klinik Araştırmalar Etik Kurulu'nun 18.09.2017 tarih ve 09 sayllı toplantısında alınmıştır.

\section{Kaynakça}

Anagnostopoulos, F. ve Hantzi, A. (2011). Familiarity with and social distance from people with mental illness: testing the mediating effects of prejudiced attitudes. Journal of Community and Applied Social Psychology, 21, 451460.

Arıkan, C.., Özdemir, V. ve Satır, M. (1989). İçinde ruh hastası olan ve olmayan ailelerin ruh hastası ve hastalıklarına yönelik tutumlarını karş̧laştıran bir çalışma. 24. Ulusal Psikizatrik ve Nörolojik Bilimler Kongresi (1988, Ankara), Tam Metin Kitab1, 411.

Bhugra, D. (1989). Attitudes towvards mental iliness: A reviewv of the literatüre. Acta Psychiatrica Scandinavica, 80, 112.

Bilge, A., Akmeșe, Z., Kocak, Y. ve Sarıcan, E. (2013). A Group of Midwifery Students' Beliefs Toward Mental Illnesses in Turkey. Balkesir Health Sciences Journal, 2, 9-14.

Bostanc1, N. ve Aştı, N. (2004). Hemşirelerin ruh sağlığı bozuk olan bireylere karşı tutum ve davranışlarının değerlendirilmesi. Düssunen Adam, 17(2), 87-93.

Bowland, S., Hensley, M. ve Johnson, B. (2010). Fleming a consumer focus groups: A key to transforming behavioral health systems? International Journal of Mental Health, 39(1), 16-28.

Cohen, J. ve Struening, E. L. (1962). Opinions about mental illness in the personnel of two large mental hospitals. Journal of Abnormal and Social Psychology, 64, 349-360.

Davidson, M. (2002). What else can we do to combat stigma? World Psychiatry, 1(1), 22-23.

DeFreitas, S. C., DeLeon, C. M. ve Ajayi, A. (2018). Perceived and personal mental health stigma in Latino and african american college students. Front Public Health, 6(49), 1-10.

Doğan, O., Kılıçkap, Z., Çelik, G. ve Çorapçığlu A.(1994). Psikiyatri stajının tıp fakültesi öğrencilerinin ruh hastalarına karşı tutumlarına etkisi I. Cumburijet Üniversitesi Trp Fakültesi Dergisi, 16, 206-210.

Duman, B., Çolak, B., Özdemir, N. S., Özkasap, S. N., Sabahi, S. İ., Şahinoğlu, B. M., Taşçı, D., Tatar, M. M., Ünalp, C., Kar, İ. ve Kumbasar, H. (2019). Tip eğitiminin ruhsal hastalıklara yönelik tutumlara etkisi. Türk Aile Hekimligi Dergisi, 23(4), 141-149.

Gaebel, W., Roessler, W. ve Sartorius, N. (2017). The stigma of mental illness - End of the story? Switzerland: Springer International Publishing.

Goffman, E. (1963). Stigma: Notes on the management of spoiled identity. New Jersey: Englewood Cliffs, Penguin Group.

Lord, C. G, Ross, L. ve Lepper, M. R. (1979). Biased assimilation and attitude polarization= the effects of prior theories on subsequently considered evidence. Journal of Personality and Social Psychology, 37(11), 2098-2109.

Martin, J. M. (2010). Stigma and student mental health in higher education. Higher Education Research \& Development, 29(3), 259-274.

Morgan, C. T. (1991). Psikolojizy giriş (Edt: S. Karakaş ve R. Eski). Ankara: Eğitim Akademi Yayınları.

Papish, A., Kassam, A., Modgill, G., Vaz, G., Zanussi, L. ve Patten, S.(2013). Reducing the stigma of mental illness in undergraduate medical education $=\mathrm{a}$ randomized controlled trial. BMC Medical Education, 13(141), 2-10.

Wolfe, B. L. ve Haveman, H. H. (2002). social and nonmarket benefits from education in an advanced economy. Conference Series. Reserve Bank of Boston, 47(97), 1-142.

Yüksel, N., Yllmaz, M., Örekici, G. ve Temel, G.(2015). Öğretim elemanlarının ruhsal hastalıklara ve hastalara ilişkin görüşleri. Psikiyatri Hemşireliği Dergisi, 6(1), 26-32.

\section{EXTENDED ABSTRACT}

The concepts of stigma and stigmatization were first defined by the field of sociology. According to the sociologist Goffman, who used the concept for the first time, the stigmatization is that the individual has; character traits, physical traits, or membership for a particular group, and are based on the assumption that the stigmatized individual is lower and dangerous than the rest of society. Stigmatization for psychiatric patients and "social stigmatization" directed from society to individuals. It is divided into two as "self-stamping" directed by the individual. Social stigma in general. As the mental disorders include the fear, avoidance, and rejection behaviors formed around the judgments that the individual is the result of his own mistakes, is incurable and the mentally ill person is dangerous it also includes feelings of shame and inadequacy developed by individuals with mental illness. Some of the negative effects of stigmatization on psychiatric patients are: a) It decreases the tendency of individuals to apply to psychiatry clinics for examination / treatment. This reduces their chances of being treated. b) Individuals with mental 
illness are unlikely to find a job due to reasons such as fear and anxiety developed for mental illness. c) Fear of exclusion that individuals with mental illness may feel may cause them to adopt a timid attitude towards life and not to evaluate the opportunities they will encounter. This reduces individuals' satisfaction with their lives; reduces their chances of realizing themselves. Some studies examining the relationship between education and stigmatization have focused on the phenomenon called attitude polarization to explain this paradoxical situation between education and attitude. According to this approach, which argues that ideas can be formed more clearly, positively or negatively after receiving detailed information about a subject, people may be more inclined to process and retain information that will strengthen their existing judgment while providing information about a subject.

The aim of this study is to investigate the relationship between stigmatization and education by measuring the stigmatization behavior of students studying in the field of health sciences. 1435 students studying at the Faculty of Health Sciences of a university in Istanbul constitute the sample of the research. The study was conducted between September 2017 and June 2018. To measure stigmatization behavior, Opinions About Mental Illness (OMI) and socio-demographic questionnaire were used.

The average age of the students was $20.54 \pm 2.37$ and $83.3 \%(n=1196)$ were female. When the differences of the scale sub-dimensions according to the sections are examined there was a statistically significant difference in authoritarianism, social restraint and interpersonal etiology sub-dimensions, and a statistically significant difference in the sub-dimension of Protection and Conservation appeared. When the differences of the sub-dimensions of the scale by classes are examined there was a statistically significant difference between the classes in the sub-dimensions of Protection and Observation and Mental Health Ideology. When the differences of the sub-dimensions of the scale according to the course existence related to "Mental Diseases and Mental Health" are examined a statistically significant difference was found in the sub-dimensions of authoritarianism and mental health ideology.

According to the results of the study, it has been observed that the perception and attitude towards mental illness in students is not at the desired level. It is thought that it is important to gain the knowledge that psychiatric diseases are not different from physical diseases from the first steps of education. In this context, it is recommended to conduct research and studies in order to include information on psychiatric diseases in accordance with the level of students in courses based on respect for differences and human rights based on primary education from the second grade. In this way, it will be possible to intervene in judgments that are difficult to change at the undergraduate level, yet at the stage of formation. On the other hand, as our study and similar studies show, having psychiatric patients in the immediate vicinity of the person is a factor that reduces negative judgments. For this reason, it is thought that it will be beneficial to encourage studies such as projects, homework, etc., where undergraduate students who will work in the field of health can meet with psychiatric patients more frequently and meet around common goals. 